\title{
Study on Co-distribution System for Agricultural Products within Beijing City
}

\author{
Xiaohui Yan \\ Beijing Polytechnic, Beijing, China
}

\begin{abstract}
Based on the investigation on the status of the existing distribution system of agricultural products in Beijing and the analysis of the current problems of distribution and the factors affecting the quality and price fluctuations of fresh produce, this paper puts forward strategies to solve the distribution problem of agricultural products and some ideas for future development.
\end{abstract}

Keywords-agricultural products; city distribution;problems and countermeasures

\section{CURRENT STATUS OF AgRicultural PRODUCTS DISTRIBUTION SYSTEM IN BEIJING}

\section{A. Meaning of the Distribution for Agricultural Products}

The connotation of agricultural products logistics is a process to deliver the agricultural products to the consumers based on the consumer's needs for agricultural products. This process consists of a series of activities, such as processing, sorting, classification, distribution, transportation and the end transportation, and takes place in agricultural distribution center, agricultural products wholesale markets, supermarket chains or other agricultural products distribution. Its extension consists mainly of two distributions: agricultural products suppliers and supermarket supply chain. The supplier distribution mainly includes the delivery process that main distribution bodies, such as the agricultural products distribution companies, agricultural products wholesale markets, professional associations of other agricultural producers, deliver the agricultural products to the major end consuming bodies: supermarkets, schools, hotels, and community and family consumers. The supermarket chain distribution is a process that the supermarket headquarters who are mainly engaged in agricultural products distribute produce from distribution centers to each distribution chain stores and other organizations.

\section{B. Current Status of Distribution}

\section{1) Current status of distribution system}

Currently, Beijing is the largest and most intensive agricultural consumer market in the world. In recent years, following the Beijing Municipal Development Plan, an initial formation of modern agricultural distribution system has been set up by combining the sources from Beijing city and other cities. This is done by taking agricultural products wholesale market as distribution centers; bazaars, retail shops, all kinds of special shops and supermarkets as basis; and a variety of marketing methods, such as modern logistics and distribution, chains and e-commerce as a means. The citywide comprehensive and regional wholesale distribution markets for agricultural products as an important part of the whole pattern for wholesale distribution products are located in East, South, West, and North of Beijing. They initially formed three large gathering areas of agricultural wholesale distribution market: the Southwest, the East, and the North of Beijing, and nine large-scale wholesale distribution markets for agricultural products: five located within Ring 5 and four located outer Ring 5 Agricultural products distribution channels in Beijing have begun to take shape and are in operation effectively. These meet the needs for the circulation of agricultural products in Beijing and consumer demands from Beijing residents, effectively protect the smooth operation and social development in the Capital, and have become an important hub for the distribution network of agricultural products in whole north China.

The distribution model for agricultural products existing in Beijing can be summarized into three types: 1)Circulation and distribution by Farmer-to-Supermarket and Farmer-to-Restaurant which accounts for about $20 \%$ of the total market; 2)Circulation distribution by Specialists; and 3) Circulation distribution via the companies plus farmers themselves. The latter two have been part of the wholesale market and currently accounting for about $80 \%$ of the total trading market.

\section{2) Current status of distribution effect}

According to statistics, the ratio of losses for agricultural products caused the logistics in China is quite high. A study conducted by National research center for the preservation engineering and technology of agricultural products had found the following: the loss rate from farm to fork for China's annual production of fruits and vegetables is as high as $25-30 \%$, while the loss rate in developed countries is generally controlled under $5 \%$. The logistics chain loss rate for fresh fruits and vegetables in the U. S. is only $1-2 \%$. Food postpartum loss rate of the United States and other developed countries is less than $3 \%$, and fruit $1.7 \%-5 \%$. About 35 percent of China's agricultural losses occurred in the logistics process which results in a small sales radius for agricultural products, difficult to transport over long distances, and also limiting the bulk of agricultural trade.

\section{ANALYSIS OF THE CAUSES FOR THE PROBLEMS}

The influencing factors of continues fluctuation of the current price of fresh agricultural products in Beijing are: 1) Price fluctuation in agricultural materials; 2) Blindness in the distribution on the planting or breeding varieties of agricultural products from farmers. Generally based on prior year sales and price effects, the fluctuations occurred in the number of breeding or cultivation;3) Packing for agricultural 
products is too primitive or simple, and no effective protection, which results in a larger loss; 4) Protective measures for fresh or living products distribution is also too primitive, for example, low temperature protection measures and protective boxes are not enough, which results in also a large loss; 5) Wholesale has much backlog. Fresh fruits and vegetables and living produce cannot timely delivery out; 6) There are not sufficient protective measures in handling and distribution processes. Last four of which factors are associated with the distribution of agricultural products, and they create more than $80 \%$ total loss. The reasons that lead to this result can be summarized in the following sections.

\section{A. Insufficient Capability in Distribution Technology}

1) Lack of standardization, quality, and safety consciousness and awareness. Standardized operating procedures in terms of logistics and distribution of fresh agricultural produce have not yet been fully established in Beijing. There are not strict temperature standards and packaging requirements in storage, processing, transport and other stages for different types of fresh agricultural produce. Studies on 100 individual distributors and 20 distribution companies for agricultural products show that only 10 companies know the relevant provisions for the fresh ice and transport packaging during fresh produce distribution.

2) Professional level uneven among distribution companies. The existing distribution companies for fresh produce, in addition to relying on a small number of large supermarket distribution company, there are fewer than 30 companies that have "fruit and vegetable distribution" or "distribution of agricultural products," registered in Trade and Industry Bureau within the name of the company. Only a few fresh produce distribution companies in Beijing have formed a specialized brand, such as Grand Canal agricultural distribution center, Xiaotangshan distribution of agricultural products, Xinfadi Distribution Center, Aojun Distributions, Xinmaodu agricultural products distribution Co. , and Haoyunlilai Ltd. Most groups actually engaged in distribution activities are self-employed or vegetable wholesale brokers.

3) Lack of a platform for complete agricultural logistics information. Currently, there are approximately 625 agricultural produce markets in operation in Beijing, including 45 agricultural products wholesale markets (18 large ones), 395 retail markets of agricultural products, 185 integrated agricultural products markets. However, the market information network that Beijing has established confined currently to product supply information, but lack of relevant information on the related logistics enterprises. A comprehensive fresh produce logistics information platform has not been established.

\section{B. Efficiency in City Distribution}

Since December 1, 2009 onwards, Beijing implemented the restrictions on the freight vehicle models and appearance for whole day and controlled the total truck traffic in urban centers throughout the day. This limited the truck van as a delivery vehicle for city distribution, and a "passenger cargo" phenomenon appeared. The study has found that most logistics companies are using the modified Jinbei cars for urban distribution. Under the same displacement, the Jinbei car's cargo capacity is only one-third of truck van's capacity. A great number of Jinbei vehicles has obviously increased a lot of traffic pressure around the produce wholesale markets and the urban area of Beijing, and also reduces the efficiency of urban distribution for fresh produce.

After April 2010, the trucks to get inside the 5th Ring are required certified documents issued by the traffic control department, and during the peak period in morning and evening they are still forbidden to drive into the 5th Ring. That the trucks meet the requirements does not mean that they can travel freely in the city. Even those standard vehicles specially for city center distribution system need also to hold a certificate issued by the traffic control department to travel within the specified access time period. The traveling time for vehicles without certified documents is from 0:00 to 6:00. The existing logistics capacity cannot meet the growing demand for agricultural produces. In this supply and demand, passenger van laden popular and urban distribution presents a complex and distorted industrial ecology.

The problems, such as truck limit line, modified Jinbei van to act as delivery trucks, un-load phenomenon, and too long time waiting for distribution etc. result in the city's transportation congestion and low distribution efficiency.

\section{MeAsures to SOlVE THE Problem}

\section{A. Improving the Security Monitoring for the Supply Chain and Distribution of Agricultural Products}

1) Strengthening production safety monitoring in agricultural production base. Establish the original locations of produces and user databases: detailed records of agricultural production environment, production scale, the use of input materials, and gradually improving the safety management system so that to make a for the foundation in order to establish a traceability system. Establish agricultural procurement standard database: the purchasing department may at any time make procurement plans and issued purchase instructions according to production base's periodic reports on species, growing, production and other product information. The timely feedback of market demands to the production base is conducive to the base to adjust production plans. Establish and improve Beijing's agricultural quality and safety management system: on the basis of the existing, from land to table for green food, the whole quality management system, develop quality management and certification system for safe agricultural products, strengthen the management of five aspects: the environments of agricultural production, agricultural investment, agricultural production process, packaging, and labeling and market access.

2) Strengthen safety testing on major wholesale markets of agricultural products. It is necessary to establish security agencies in agricultural products wholesale market. These agencies will detect whether there are left-listed agricultural pesticides on produces or not, whether there is a high risk of 
agricultural products. It should establish information database for high risk of agricultural products, change the traditional model of market regulation, and constantly improve the level of standardization of hardware and wholesale management modernization, upgrade the capacity for market management, operation and services, and achieve scientific supervision to ensure the safety of agricultural products in the Capital.

To ensure the safety of agricultural products, the regulatory authorities should implement measures such as on-site management, "real-time" monitoring, and staggering enforcement to increase law enforcement forces, forward regulatory pass, change later discipline to advance prevention, apply control during the events, and improve regulatory efficiency. Major wholesale markets implement linkage disciplines to operators. The city established a unified system of market integrity. Through self-regulatory approach, the city needs to strengthen agricultural products wholesale market's management for illegal actions and unqualified goods, raise the cost of illegal cases, combat the illegal actions, and enhance market order.

3) Strengthen safety examining and monitoring in the distribution of agricultural products. It is necessary to strengthen supervision and monitoring of the distribution process of agricultural products to supermarkets, restaurants, and retailers to prevent the deterioration of products in the first two sessions due to various reasons such as the limits on delivery vehicles and facilities, or the change of some internal and external conditions, the climate change or the changes in other natural factors. The effort should be paid to avoid deterioration of agricultural products to the final consumer's hands, as it related to the vital interests of consumers. In this session more monitoring needs to be applied. For those supermarkets, restaurants, and retailers that sold expired and deterioration of produces more punishment needs to be implemented.

\section{B. Take Measures to Reduce Logistics Costs}

1) Improve toll road policy. Beijing will facilitate access for fresh produce transportation vehicles to the city, while clearly emphasizes the nonprofit of agricultural products wholesale and community markets.

2) Establish a common agricultural distribution alliance. Alliance members include the supply and the demand sides. Both sides understand the market dynamics via supply and demand information platform, which will not only avoid batch supplier delivery, but also make the demand side quickly obtain a wide range of needs.

3) Increase the coverage of agricultural community distribution stations. In order to solve the "last mile" delivery problem in produces, start the city logistics "joint distribution" stations. Through the integration of distribution resources at urban logistics service ends, achieve that within a radius of one kilometer of a community or school set up joint distribution centers by the courier companies and e-commerce enterprises in the same area to reduce distribution costs.

4) Other aspects for policy support. In terms of value-added tax reform and the tax policy for the land usage by commodity storage facilities, reduce the burden of corporate taxes and operating costs for the logistics companies. Beijing will give priority to the development of agricultural product logistics; support financial and insurance institutions to provide financing services for agricultural logistics enterprises, encourage social funds to invest in agricultural logistics industry, and support listing the qualified logistics enterprises after restructuring.

\section{Establish and Improve the Supply Chain and Distribution of Agricultural Products}

Establish the agricultural supply chain taking various types of enterprises as the core by learning from foreign practices. From farmers and all kinds of companies to the consumer, construct production and distribution networks. Establish a stable agricultural supply chain system and implement comprehensive management on logistics, capital flow, and information flow. Undertake processing, packaging, transportation, storage, handling, messaging, sales and other business for agricultural products. The members of the same supply chain should follow so-called " order trading principle" to establish a more stable relationship.

\section{Build a Unified Information Platform of Agricultural Products}

Establish agricultural information platform on the basis of perfect material and technical infrastructure; Collect and disseminate information and related agricultural policies and regulations; Monitor the entire supply chain; Supply chain members can easily carry out e-commerce activities. The information between supply chain members will be seamless docking to accelerate supply chain operations speed and reduce the total cost of the supply chain. Supply chain members, in an integrated information system, will establish an integrated logistics system and improve the efficiency of logistics operations. Redesign the logistics chain for process of production, processing and distribution to make agricultural logistics operations seamlessly. Network the logistics base, agricultural products distribution routes, means of transportation in order to improve the efficiency of logistics activities and reduce logistics costs.

\section{CO-DISTRIBUtION MODEl FOR AGRICULTURAL PRODUCTS}

\section{A. Farm-Supermarket Interface}

Build a platform for high-quality agricultural products into supermarkets: farmers and merchants sign intent agreement; by the way that the farmers directly supply agricultural products to supermarkets, markets and convenience stores, connect the big markets with millions of households and small-scale production, and build integrated production and marketing chain under market economy conditions to realize the win-win among businessmen, farmers, and consumers.

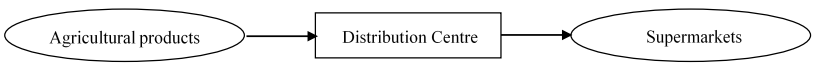




\section{B. Farm-Community Interface}

Build a platform for high-quality agricultural products into the community: farmers and consumers reach intent agreement; by the way that the farmers direct supply agricultural products to the consumer community, connect the big markets formed by the varied social communities with millions of households and small-scale production, and build a marketing integration chain under economic conditions so that to realize the win-win between farmers and consumers.

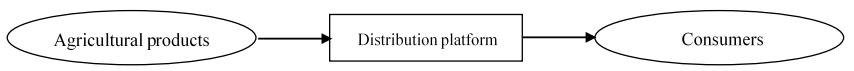

\section{Farm-Trade Interface}

Farmers market are mostly operated by small business or individual business. They purchase dozens of vegetables for residents' needs by themselves to second wholesale market. With a unified information platform and logistics distribution center, and using specialized distribution company that directly supplies these markets, at first, it can intensive resources, secondly it can specialize the work, thirdly, collective procurement can reduce costs so that reduce the real price of vegetables.

\section{Farm-Family Interface}

Farm-Family Interface is in general for white-collar workers, the families with the elderly, children, pregnant women, and high-income. It mainly distributes ready-to-cook products, nutrition package cuisine, organic vegetables, organic produce, organic eggs, and organic meats.

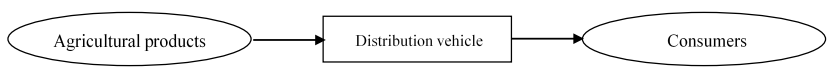

\section{REFERENCES}

[1] Chan Juan, Han Yongsheng and Liu Yanping, The design and study of urban logistics joint distribution model and system architecture. [J] Urban Observatory, No. 4, 2013

[2] Zhang Lu Fang, Xu Jie, Analysis of the application of the city joint distribution pattern at the end of e-commerce. [J] Logistics Technology, No. 6, 2013.

[3] Analysis of the China's joint distribution development, Logistics Technology and Application [J], No. 4, 2013.

[4] Cheng Haixing, Ma Yanqiang, International experience and learning from the development of joint distribution. [J] Logistics Technology and Application No. 4, 2013. 